\title{
Severe failure to thrive and diarrhoea caused by laxative abuse
}

\author{
A C FENTON, M P WAILOO, AND M S TANNER
}

Department of Child Health, Leicester Royal Infirmary

SUMMARY We report a case of chronic administration of Epsom salts leading to diarrhoea and severe weight loss in a 7 month old girl.

Failure to thrive in association with loose stools is a frequent diagnostic problem. We report our experience.

\section{Case report}

A girl, weighing $2500 \mathrm{~g}$, was born at 41 weeks' gestation to a young single mother. At age 3 months she developed 'pertussis', then presented one month later with poor feeding, lethargy, weight loss, and passage of six to ten loose stools per day. She was admitted to hospital where breast feeding was supplemented with bottle feeds. All investigations gave normal results (sweat test, thyroid function tests, stools for occult blood and microbiology, and blood for routine haematology and biochemistry). The child recovered and was discharged after six days. Two weeks later she developed typical chicken pox and received antibiotics for a 'chest infection'. Although weight increased slowly, her stools remained loose and frequent.

During the next two weeks she was treated by the family practitioner for another chest infection and was also thought to have had rubella.

The health visitor became increasingly concerned about her 'failure to gain weight' and continued watery stools despite the child being alert and feeding well. On readmission, age 0.58 years, she weighed $4190 \mathrm{~g}$ (below the 3rd centile). Investigations were performed including repeated stool bacterial and viral culture, stool chromatography, serum lipids, radiography of long bones, serum immunoglobulins and T cell subsets; all gave normal results. In view of her numerous illnesses, a secondary cows' milk protein intolerance was suspected and a change to a soya milk resulted in an immediate but temporary improvement. This pattern of temporary improvement was repeated several times with other empirical feed changes. During three weeks in hospital mother and baby were inseparable, with the mother remaining calm and smiling throughout.

After a weekend at home she was readmitted in a severely dehydrated state, and after resuscitation intravenous feeding was commenced. Intermittent diarrhoea continued but collection of stool samples proved difficult. Eventually stool electrolytes were analysed. A large solute gap existed between measured osmolarity $(284 \mathrm{mmol} / \mathrm{kg})$ and measured electrolytes (sodium $<5 \mathrm{mmo} / \mathrm{l}$, potassium 15.4 $\mathrm{mmol} / \mathrm{l}$, chloride $23 \mathrm{mmol} / \mathrm{l}$ ). Urine contamination was excluded by a low faecal urea. Sugars including lactulose were absent. Faecal magnesium was $170 \mathrm{mmol} / \mathrm{l}$, which, for her approximately measured daily stool volume, was equivalent to $4.5 \mathrm{mmol} / \mathrm{kg} / 24$ hours (about 10 times normal). Urinary magnesium was also high (again 10 times normal) though plasma magnesium remained normal due to high urinary clearance. Confronted with this information the mother admitted to administering Epsom salts so that symptoms were maximised and 'the doctors would take her more seriously'. A box of Epsom salts $(58 \mathrm{~g})$, a feeding bottle containing $350 \mathrm{mmol} / \mathrm{l}$ of magnesium, and some distilled water were found in her possession. After separation from the mother

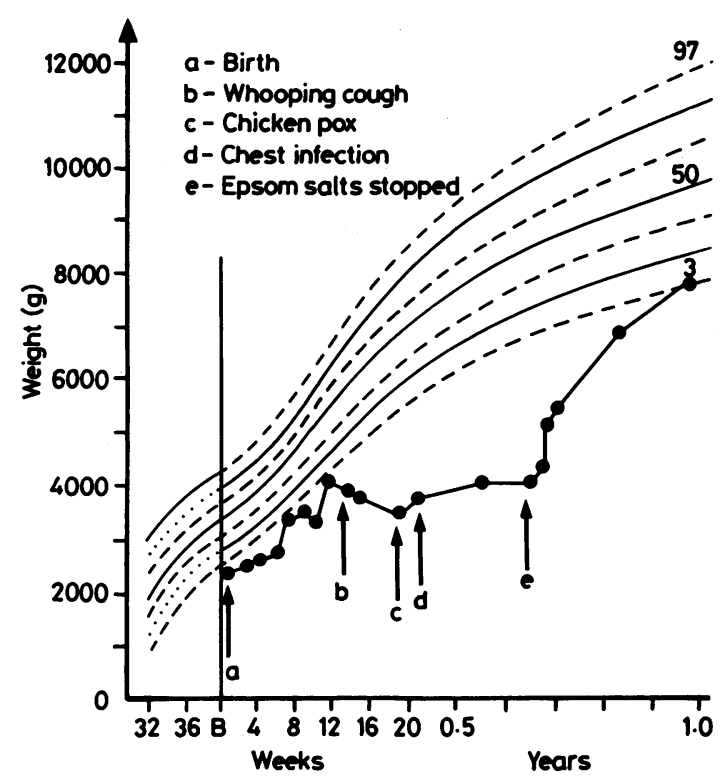

Figure Poor weight gain in an infant found to have been receiving Epsom salts, and subsequent rapid catch up growth. 
and subsequent fostering the diarrhoea ceased and the child's weight gain was dramatic (figure).

\section{Discussion}

The deliberate administration of harmful substances was included in early descriptions of child abuse. ${ }^{1}$ These substances include both household products and drugs, which were often prescribed for adults in the family. ${ }^{2}$ Previous reports have emphasised that a prerequisite for diagnosis is a low threshold of suspicion. ${ }^{34}$ Disturbances of bowel function with poor weight gain are commonly seen in infants, but reports of deliberate overdosing with dangerous drugs are relatively uncommon, and laxative abuse in very young children is exceedingly rare. These factors, the exemplary behaviour of the parents, and the trust which doctors place in parental histories, militate against early diagnosis with potentially life threatening consequences.

Even when the diagnosis is considered, proving it is often difficult and in this case the stool electrolytes were vital in distinguishing an osmotic from a secretory diarrhoea. The severity of weight loss and the near fatal episode of dehydration emphasises the need to consider pharmacological abuse where the clinical picture is unusual. ${ }^{2}$

\section{References}

' Kempe CH, Silverman FN, Steele BF, Droegemueller W, Silver HK. The battered child syndrome. JAMA 1962;181:17-24.

${ }^{2}$ Rogers D, Tripp J, Bentovin A, Robinson A, Berry D, Goulding R. Non-accidental poisoning: an extended syndrome of child abuse. Br Med J 1976;i:793-6.

${ }^{3}$ Meadow R. Munchausen syndrome by proxy. The hinterland of child abuse. Lancet 1977;ii:343-5.

${ }^{4}$ Watson JBG, Davies JM, Hunter JLP. Non-accidental poisoning in childhood. Arch Dis Child 1979;54:143-4.

Correspondence to Dr MS Tanner, Department of Child Health, Clinical Sciences Building, Leicester Royal Infirmary, PO Box 65, Leicester LE2 7LX.

Accepted 7 March 1988

\section{Clostridium difficile in an oncology unit}

\section{A L BRUNETTO, ${ }^{*}$ A D J PEARSON,* A W CRAFT,* AND S J PEDLER $\dagger$ \\ *Department of Child Health, The Medical School, University of Newcastle upon Tyne, and †Department of Clinical Microbiology, Royal Victoria Infirmary, Newcastle upon Tyne}

SUMmaRY In one year 21 new cases of Clostridium difficile infection occurred on a paediatric oncology unit. Eleven cases were in a two month period. This infection should be regarded as a communicable disease. Investigations to detect $C$ difficile should be carried out in children with malignant disease who have diarrhoea.

Clostridium difficile has been increasingly recognised as an aetiological agent of acute and chronic antibiotic associated diarrhoea and pseudomembranous colitis. ${ }^{1}$ There have been reports of outbreaks in hospital units as well as sporadic cases. Patients with malignant disease receiving immunosuppressive treatment are at risk of opportunistic infection. As they also receive numerous courses of antibiotics and have frequent hospital admissions throughout their treatment they are at particular risk of $C$ difficile infection. ${ }^{2}{ }^{3}$ In addition cancer chemotherapy may predispose to gut colonisation with $C$ difficile. ${ }^{3}$ We report an outbreak of infection with this organism in a paediatric oncology unit associated with a change in antibiotic policy.

\section{Patients and methods}

All patients admitted to the paediatric oncology unit, a 10 bedded ward exclusively for children with cancer, in Newcastle upon Tyne during 1986 who had diarrhoea associated with $C$ difficile were included in this study. Diarrhoea was defined as a change from normal bowel pattern with passage of two or more consecutive unformed stools. Stool specimens from patients with diarrhoea were examined for the presence of $C$ difficile and its cytotoxin in addition to routine virological and bacteriological investigations.

Specimens were inoculated onto Columbia blood agar containing cycloserine and cefoxitin as selective agents. Detection of cytotoxin was performed by standard laboratory methods. ${ }^{4}$

Since 1981 patients on the unit with neutropenia and fever have received empirically gentamicin and azlocillin. During 1985 only $61 \%$ of Gram negative bacilli isolated were sensitive to azlocillin, therefore in March 1986 cefuroxime was substituted for azlocillin.

Because of an apparent increase in the number of patients with $C$ difficile infection early in 1986, stool 